
\title{
28 Research Square \\ Ultrasound feature discordance in a bilateral juvenile ovarian granulosa cell tumor: A case report
}

\section{Li Zhang}

Peking Union Medical College Hospital

Sheng Cai ( $\nabla$ caishengpumch@126.com )

Peking Union Medical College Hospital

\section{Yahong Wang}

Peking Union Medical College Hospital

\section{Ying Wang}

Peking Union Medical College Hospital

\section{Zhitong Ge}

Peking union medical college hospital

\section{Mi Zou}

Peking union medical college hospital

\section{Jianchu Li}

Peking union medical college hospital

Huifang Huang

Peking union medical college hospital

\section{Case report}

Keywords: juvenile ovarian granulosa cell tumor, ultrasound, cystic mass, bilateral, unilocular cyst

Posted Date: January 13th, 2021

DOI: https://doi.org/10.21203/rs.3.rs-143384/v1

License: (c) (1) This work is licensed under a Creative Commons Attribution 4.0 International License.

Read Full License 


\section{Abstract}

\section{Background}

As a rare ovarian stromal tumor, the juvenile ovarian granulosa cell tumor (JGCT) is mainly seen in premenstrual and young women. It associates with high malignancy and recurrence rate, and early diagnosis and treatment could improve prognosis. Most cases are unilateral solid-cystic or solid masses, while unilocular cystic masses are rarely seen. As cystic ovarian tumors are often misdiagnosed as benign cystic lesions or functional cysts, cystic JGCT should not be overlooked.

\section{Case presentation}

We report this special case of a 10-year-old female patient. It's the first reported JGCT with completely inconsistent bilateral imaging manifestations, including an extremely rare unilocular cystic JGCT. A large solid-cystic JGCT appeared in her left ovary, and left adnexal resection was performed. A unilocular cyst occurred in the right ovary two years later. It was with a regular shape and smooth inner wall, mimicking a benign cyst. Since the patient was young and had the desire to preserve the right ovary, follow-up was initially recommended. However, the cyst size increased rapidly and exploratory laparotomy was finally performed. Pathology showed a unilocular cystic JGCT.

\section{Conclusions}

As cystic masses in young patients are easily misdiagnosed as benign or physiologic lesions, this case emphasizes the importance of postoperative follow-up for JGCTs. Exploratory laparotomy of persistent cystic lesions should be considered when necessary.

\section{Background}

Juvenile ovarian granulosa cell tumors (JGCTs) are rare ovarian stromal tumors, accounting for approximately $0.1 \%-0.3 \%$ of all ovarian tumors ${ }^{1,2}$. Approximately $90 \%$ of patients are younger than 30 years old at the time of diagnosis, and $50 \%$ are less than 10 years old ${ }^{3,4,5}$. Compared with adult ovarian granulosa cell tumor, JGCT associates with high malignancy and recurrence rate, and early diagnosis and treatment could improve prognosis.

Most JGCTs are cystic-solid masses, while cystic especially unilocular cystic JGCTs are rarely reported. To our knowledge, only 2 unilocular cystic JGCTs have been reported ${ }^{3,6}$. Besides, most JGCTs are unilateral, and only 4 cases of bilateral JGCTs have been reported ${ }^{3,7}$. JGCTs with completely inconsistent bilateral imaging manifestations have not been reported.

As cystic ovarian tumors are often misdiagnosed as benign cystic lesions or functional cysts, cystic JGCT should not be overlooked. 


\section{Case Presentation}

A 10-year-old female patient was referred to our hospital and complained of persistent abdominal pain for 2 weeks. She experienced menarche 1 year ago, and her second but last period was 7 months ago.

Transabdominal ultrasound examination showed no abnormalities in the uterus. A $23.0 \times 16.4 \times 7.2 \mathrm{~cm}$ hypoechoic mass was observed in the abdomen and pelvic cavity. Its boundary was clear, with honeycomb-like multiple small anechoic areas scattered inside. Color doppler flow imaging showed moderate blood flow signals inside (Fig. 1). The left ovary was not displayed and the right ovary had a normal appearance. Pelvic contrast-enhanced MRI showed a giant pelvic multilocular solid-cystic mass with significant enhancement (Fig. 2). Serum factors were elevated as follows: progesterone > $40.00 \mathrm{ng} / \mathrm{ml} \uparrow(0.38-2.28 \mathrm{ng} / \mathrm{ml})$, estradiol was $514.00 \mathrm{pg} / \mathrm{ml} \uparrow(27-122 \mathrm{pg} / \mathrm{ml})$, blood LDH was 335 $\mathrm{U} / \mathrm{L} \uparrow(0-300 \mathrm{U} / \mathrm{L})$, and neuron-specific enolase (NSE) was $26.8 \mathrm{ng} / \mathrm{ml} \uparrow(0-16.3 \mathrm{ng} / \mathrm{ml})$.

Exploratory laparotomy showed a left ovarian mass. Thus, left adnexal resection was performed. Pathology showed a left ovarian juvenile granulosa cell tumor (JGCT). The right ovary was normal and reserved. A left ovarian JGCT (stage IC) was diagnosed, and postoperative chemotherapy was performed.

Regular follow-up showed no abnormalities. Two years later, Transabdominal ultrasound showed a $4.8 \times 3.5 \times 3.5 \mathrm{~cm}$ anechoic mass in the right ovary with a regular shape and smooth inner wall. The serum estrogen and progestin levels were normal. A physiological cyst was considered, and follow-up was continued. In the next 6 months, this cystic mass gradually increased in size to become a giant unilocular cystic mass measuring $21.3 \times 18.1 \times 9.9 \mathrm{~cm}$, with a regular shape and smooth inner wall. Few blood signals were observed. Multiple small follicles ranging from 0.5 to $1 \mathrm{~cm}$ in diameter could be seen around the mass (Fig. 3). Serum estradiol was elevated to $171 \mathrm{pg} / \mathrm{ml} \uparrow(27-122 \mathrm{pg} / \mathrm{ml})$, while other factors' levels were in the normal range. Right adnexal resection was performed, and pathology showed a unilocular cystic JGCT (Fig. 4). She received postoperative chemotherapy, and no recurrence was found in the following 15 months.

\section{Discussion And Conclusion}

JGCTs are mainly divided into three types based on their sonographic appearance: cystic-solid, solid and cystic masses ${ }^{6.8-10}$.

Most JGCTs are cystic-solid masses with diameters greater than $5 \mathrm{~cm}$ in diameters. The characteristic sonographic appearance is predominantly hypoechoic solid mass, with multiple small anechoic areas scattered inside, indicating a "Swiss cheese sign". Cystic-solid JGCTs have relatively regular shapes and clear boundaries, with relatively rich blood flow signals in the solid part.

Most solid JGCTs were smaller than $5 \mathrm{~cm}$ in diameter. They are likely to be inhomogeneous hypoechoic, with regular shape and clear margins. Color Doppler flow imaging shows minimal or moderate blood signals. 
Cystic JGCTs are rare, and most are multilocular cystic masses with thick cyst walls and septa. Some cystic portions may contain diffuse, homogeneous, low-level internal echoes. Color Doppler flow imaging shows minimal blood signals on the wall and septa. Unilocular cystic JGCTs are rarely seen, and only 2 cases have been reported ${ }^{3,6}$.

Cystic JGCTs should be differentiated from functional ovarian cysts, teratomas, endometriotic cysts and other benign ovarian cystic lesions. It's difficult to distinguish them by imaging features alone, but increased serum factors such as anti-Mullerian hormone (AMH) and estrogen levels might be helpful for predicting ovarian granulosa cell tumors ${ }^{11,12}$. Surgery is the most important treatment for JGCTs $s^{13,14}$.

In this case, the patient had a giant left ovarian cystic-solid JGCT at the first onset and a giant right ovarian unilocular cystic JGCT two years later. As ovarian JGCTs have extremely low morbidity, the characteristics of this case were as follows: 1) bilateral JGCTs; 2) completely inconsistent bilateral ultrasonic imaging features; and 3) a unilocular cystic JGCT on one side. All these characteristics described above are extremely rare. This is the first case of bilateral JGCTs with significantly inconsistent imaging findings as well as a unilocular cystic mass, which is rare and can be easily mistaken as a benign cystic lesion.

Cystic ovarian tumors are often misdiagnosed as benign cystic lesions or functional cysts. As JGCTs are more commonly seen in young women, they are more likely to be misdiagnosed. This case suggests the importance of postoperative follow-up for JGCTs. Exploratory laparotomy is still necessary when cystic lesions gradually increase in size and do not disappear after months of follow-up.

\section{Abbreviations}

JGCT, juvenile ovarian granulosa cell tumor

\section{Declarations}

\section{Ethics approval and consent to participate}

Our study design and protocol were approved by the ethics committee of Peking union medical college hospital, and written informed consent of the patient to participate was obtained.

\section{Consent for publication}

Consent Written, informed consent for publication was obtained from the patient for publication of this case report. Publication was approved by all authors and tacitly or explicitly by the responsible authorities where the work was carried out.

\section{Availability of data and materials}

Not applicable. 


\section{Competing interests}

The authors and author institutions have no conflicts of interest.

\section{Funding}

None.

\section{Authors' contributions}

ZL wrote and edited the article. CS guided the case analysis and writing of the paper. Other authors contributed to discussion and provided clinical data.

Acknowledgements

\section{Our first acknowledgement is to our patient, a strong girl who willingly gave her clinical information to this case report. We thank the doctors and nurses in obstetrics and gynecology department in Peking Union Medical College Hospital.}

\section{References}

1. S.T. Schumer, S.A. Cannistra, Granulosa cell tumor of the ovary, J. Clin. Oncol. 21(6) (2003) 1180-9.

2. N. Mansouri-Attia, S.K. Tripurani, N. Gokul, H. Piard, M.L. Anderson, K. Eldin, S.A. Pangas, TGFbeta signaling promotes juvenile granulosa cell tumorigenesis by suppressing apoptosis, Mol. Endocrinol. 28(11) (2014) 1887-98.

3. R.H. Young, G.R. Dickersin, R.E. Scully, Juvenile granulosa cell tumor of the ovary. A clinicopathological analysis of 125 cases, Am. J. Surg. Pathol. 8(8) (1984) 575-96.

4. G. Calaminus, R. Wessalowski, D. Harms, U. Gobel, Juvenile granulosa cell tumors of the ovary in children and adolescents: results from 33 patients registered in a prospective cooperative study, Gynecol. Oncol. 65(3) (1997) 447-52.

5. L. Merras-Salmio, K. Vettenranta, M. Mottonen, M. Heikinheimo, Ovarian granulosa cell tumors in childhood, Pediatr. Hematol. Oncol. 19(3) (2002) 145-56.

6. Y. Inada, G. Nakai, K. Yamamoto, T. Yamada, Y. Hirose, Y. Terai, M. Ohmichi, Y. Narumi, Rapidly growing juvenile granulosa cell tumor of the ovary arising in adult: a case report and review of the literature, J Ovarian Res 11(1) (2018) 100.

7. M. Brisigotti, G. Fabbretti, F. Pesce, R. Gatti, A. Cohen, G. Parenti, F. Callea, Congenital bilateral juvenile granulosa cell tumor of the ovary in leprechaunism: a case report, Pediatr Pathol 13(5) (1993) 549-58. 
8. A.M. Gittleman, A.P. Price, C. Coren, M. Akhtar, V. Donovan, D.S. Katz, Juvenile granulosa cell tumor, Clin. Imaging 27(4) (2003) 221-4.

9. M. Horta, T.M. Cunha, Sex cord-stromal tumors of the ovary: a comprehensive review and update for radiologists, Diagn Interv Radiol 21(4) (2015) 277-86.

10. K.R. Rusterholz, W. MacDonald, An Unusual Case of Juvenile Granulosa Cell Tumor of the Ovary, Radiol Case Rep 4(1) (2009) 178.

11. U.M. Haltia, M. Hallamaa, J. Tapper, J. Hynninen, H. Alfthan, B. Kalra, O. Ritvos, M. Heikinheimo, L. Unkila-Kallio, A. Perheentupa, A. Farkkila, Roles of human epididymis protein 4, carbohydrate antigen 125 , inhibin $B$ and anti-Mullerian hormone in the differential diagnosis and follow-up of ovarian granulosa cell tumors, Gynecol. Oncol. 144(1) (2017) 83-89.

12. R.A. Rey, C. Lhomme, I. Marcillac, N. Lahlou, P. Duvillard, N. Josso, J.M. Bidart, Antimullerian hormone as a serum marker of granulosa cell tumorsof the ovary: comparative study with serum alpha-inhibin and estradiol, Am. J. Obstet. Gynecol. 174(3) (1996) 958-65.

13. J.L. Powell, C.A. Kotwall, B.C. Shiro, Fertility-sparing surgery for advanced juvenile granulosa cell tumor of the ovary, J. Pediatr. Adolesc. Gynecol. 27(4) (2014) e89-92.

14. D. Zhao, Y. Song, Y. Zhang, B. Li, Outcomes of fertility-sparing surgery in ovarian juvenile granulosa cell tumor, Int. J. Gynecol. Cancer 29(4) (2019) 787-791.

\section{Figures}



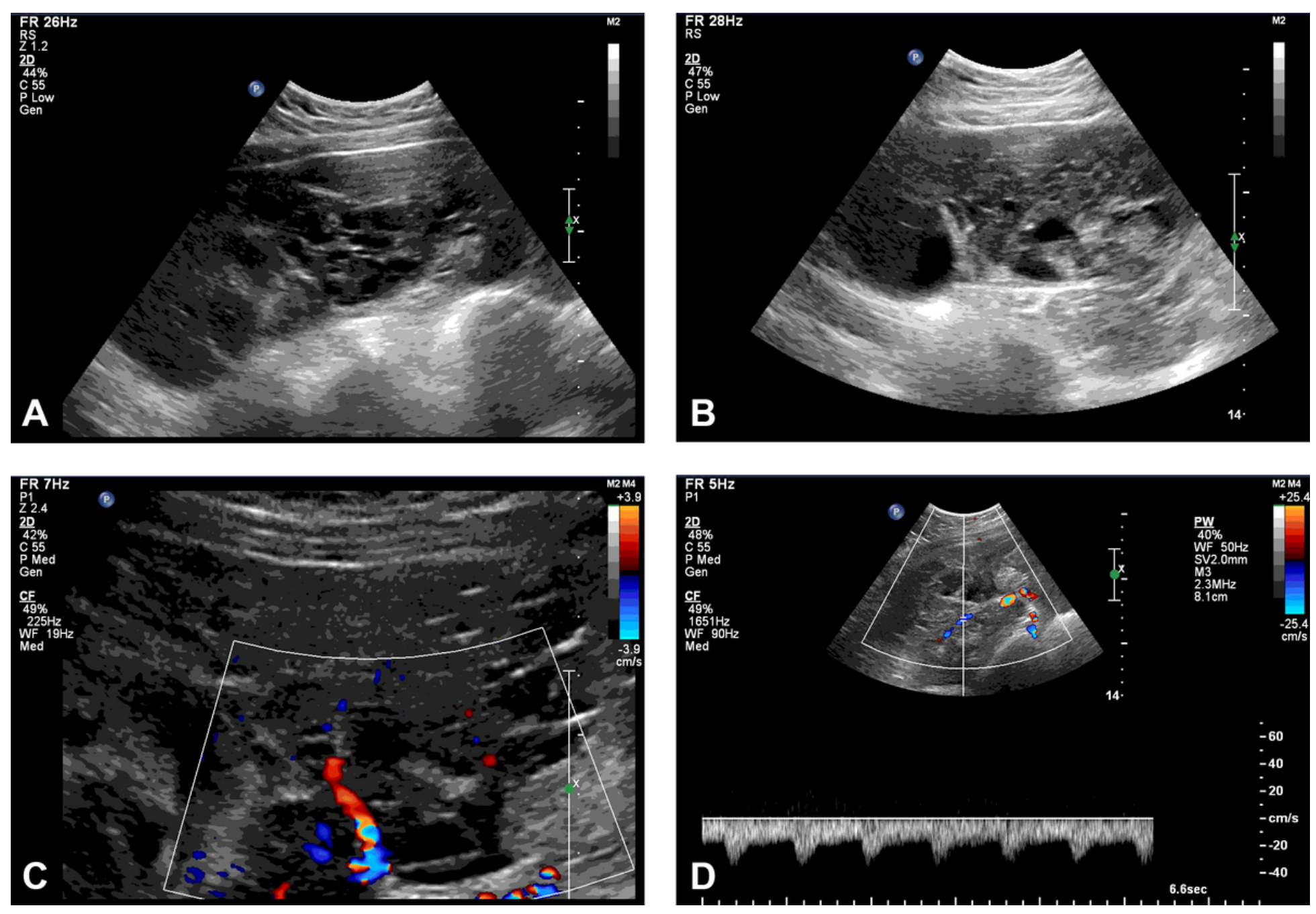

Figure 1

Transabdominal image of the left ovarian mass. A. Long-axis view; B. Short-axis view; C. Color Doppler flow image; D. Pulsed wave Doppler image. A $23.0 \times 16.4 \times 7.2 \mathrm{~cm}$ hypoechoic mass with a clear boundary was observed in the abdomen and pelvic cavity. There were several small anechoic areas scattered inside. Color Doppler flow imaging showed moderate blood flow signals inside. 

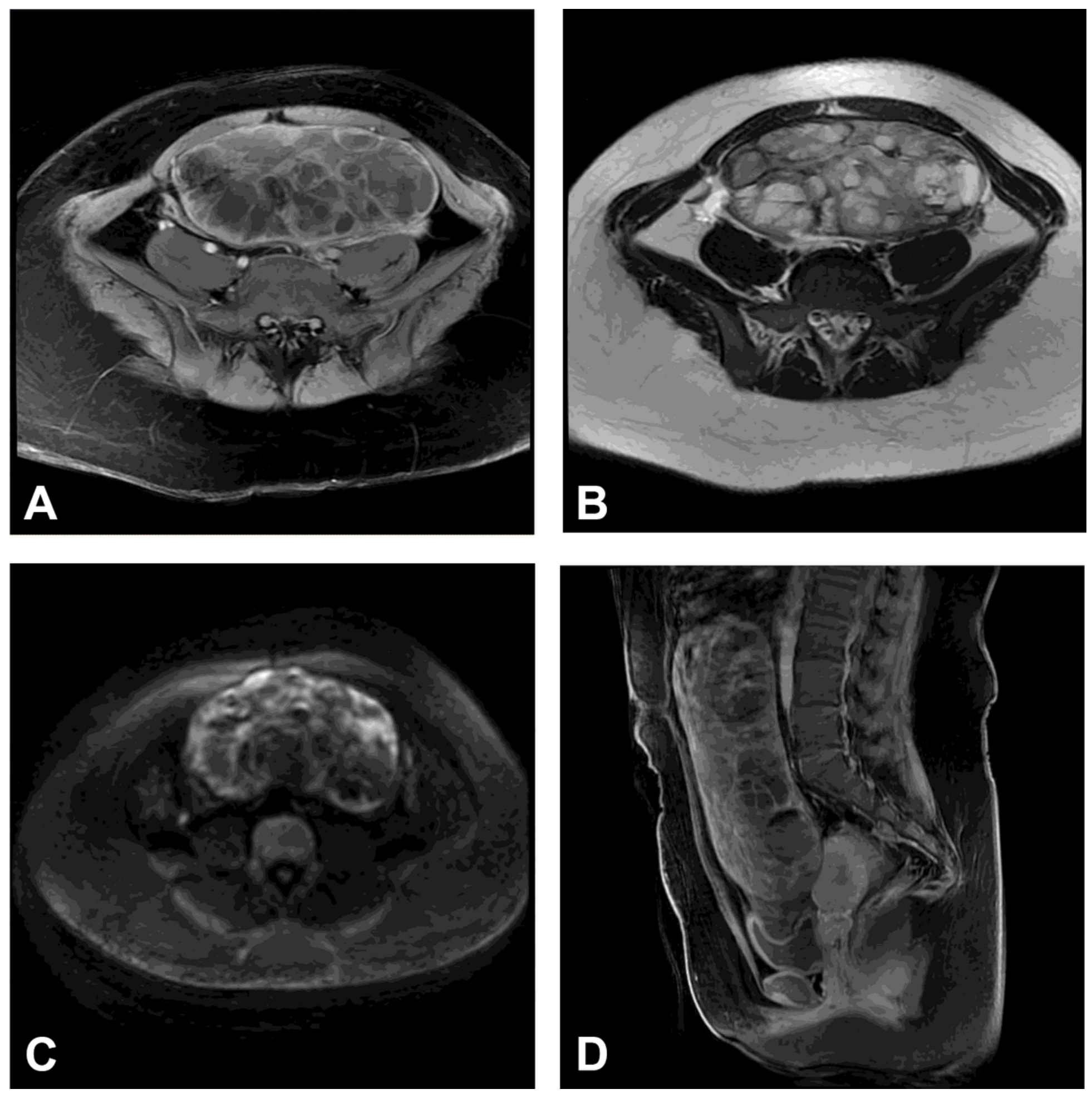

\section{Figure 2}

MRI of the left ovarian mass. A. Axial T1WI-enhanced scan; B. Axial T2WI scan; C. Diffusion-weighted imaging; D. SagittalT2WI scan. Pelvic contrast-enhanced MRI showed a giant pelvic multilocular solidcystic mass with significant enhancement. 

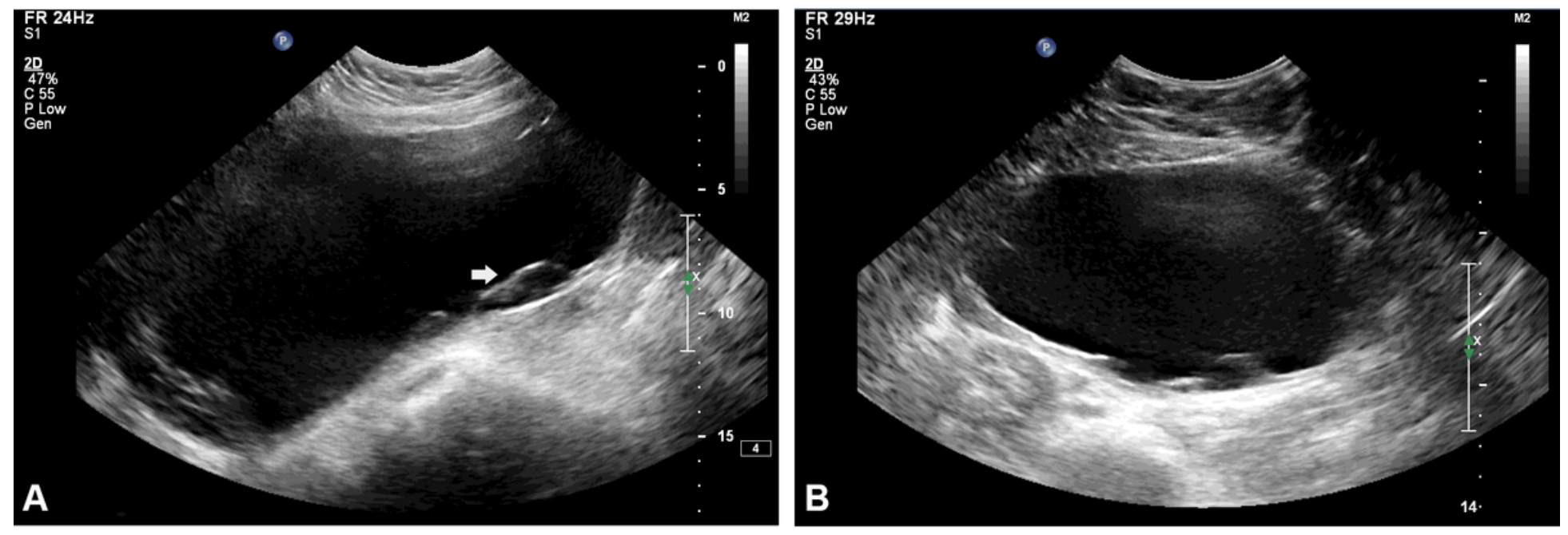

\section{Figure 3}

Transabdominal image of the right ovarian mass. A. Long-axis view; B. Short-axis view. A mass $21.3 \times 18.1 \times 9.9 \mathrm{~cm}$ in size was observed in the pelvic cavity, with a regular shape and smooth inner walls. Multiple small follicles (arrow) ranging from 0.5 to $1 \mathrm{~cm}$ in diameter could be seen around the mass. 


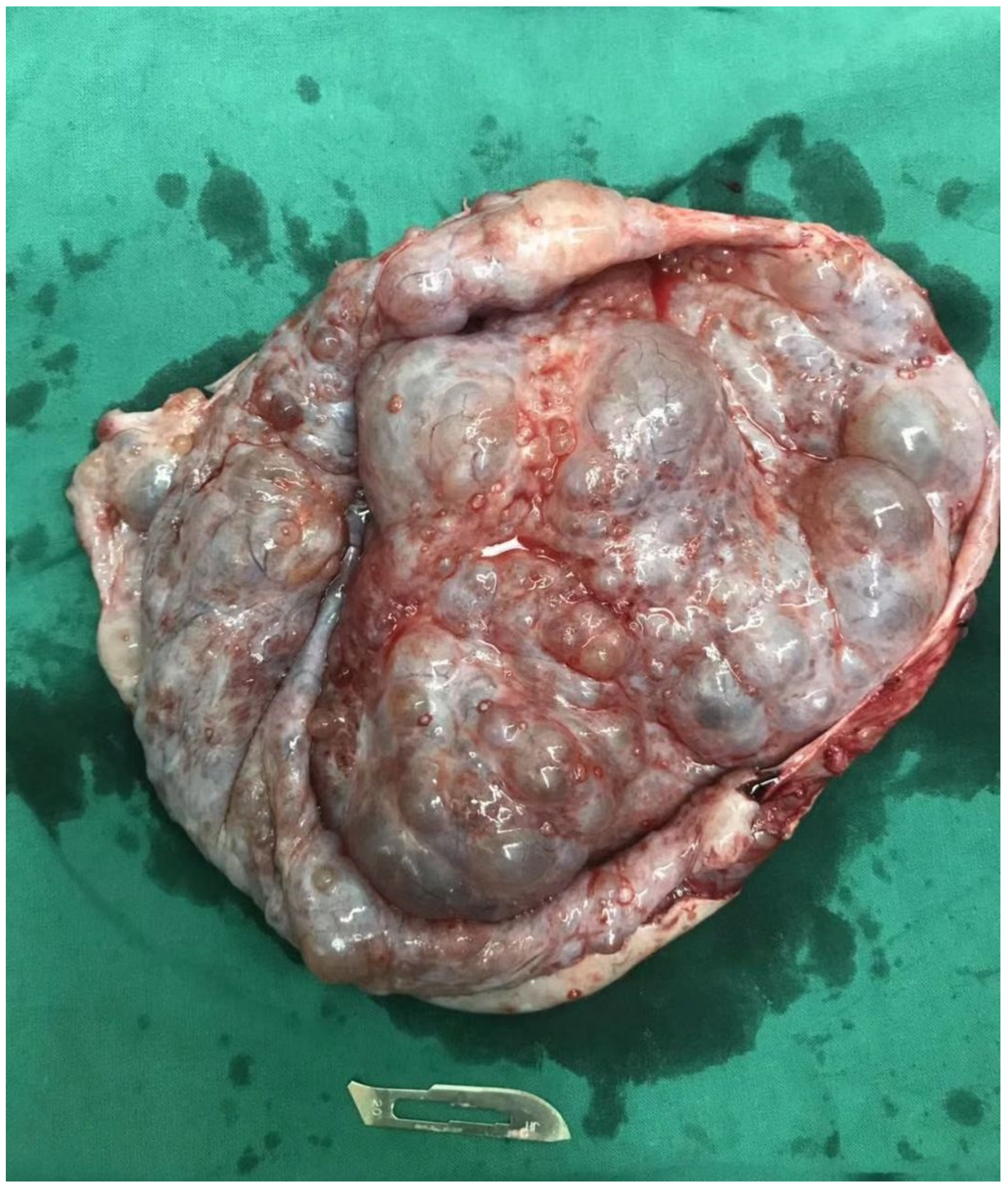

\section{Figure 4}

Right ovarian mass. A giant unilocular sac with smooth inner wall and clear fluid inside was seen in the pelvic cavity. Pathology showed JGCT. Multiple small ovarian follicles could be seen around the mass. 